\title{
Affording Creativity and New Media Possibilities
}

\author{
Zoie So \\ Department of Visual Studies, Lingnan University \\ 8 Castle Peak Road, Tuen Mun \\ Hong Kong SAR \\ zoieso@ln.edu.hk
}

\begin{abstract}
Developers compete to design the computational commodity with the most user-friendly interface. While this allows massification, it also defines boundaries. In operating these devices, users are afforded little creative freedom. We do well to question a technology that is not conducive to freedom. By no means should our interactions with computers force us into robotic submission. Following commands unreflectingly only serves to dull the mind. On the other hand, designing programs that allow users to decide over operational parameters serves to point the direction to human technological freedom. They share a common approach to the object, which should adjust to the body as the body does to it, in a reciprocal alliance that responds to particular situations. In addition, DIY and studio art practices afford the necessary skills and mindsets for sensible HCI and yield us the power to optimize our chances of designing a world defined by openness.
\end{abstract}

Keywords: Affordance, Creativity, Skill Development, Coupling, Embodiment, Disembodiment, DIY, Frugal Innovation, Studio Art, Modular Design, Openness.

\section{Introduction}

The addition of some specimen of computational technology to every aspect of human life has spawned in us an augmented sense of technophobia. Immersed in a lake of digital technology, our inner fear drifts to its reflection at the surface. The fear is caused in part by users' passive compliance with electric power machines and their mysterious intelligence. Apocalyptic dreams of robotic dominance or the end of electric power are popular themes for sci-fi plots ${ }^{1}$. Humans paralyze and gradually dehumanize, corrupted by convenience, efficiency, and computational accuracy. Homo-sapiens evolves into a sheepish homo-babulus, as digital intelligence gains omniscience and rises to omnipotence. Though these musings seem exaggerated and unrealistic, it is in fact not difficult to discern the tendencies in our everyday

\footnotetext{
1 A list of some technophobic novels as example is: Frankenstein (1818) by Mary Shelley, The Island of Dr. Moreau (1896) by H.G. Wells, Cell (2006) by Stephen King. In addition, Sci-Fi movies such as Metropolis (1927), 2001 Space Odyssey (1968), The Terminator (1984), Wall-E (2008), and Avatar (2009) can dramatically display such fear.
} 
applications of computational technology that resonate with such a dreadful reality. Fascinated by the ever new capacities of cutting-edge, state-of-the-art computation, it would nonetheless be sapient to consider their influence over users -a.k.a. human beings. In this paper I aim to illustrate that while most existing Human-Computer Interaction (HCI) design models still feed technological dependence, there is however innumerable means of developing technology in ways that inspire creativity and are conducive to the users' innate bent for innovation. I declare our mission to identify this potential and to support thereby the realization of our will for a sensible HCI: our gift to future generations.

\section{Computation's Complexity and Simplicity}

To begin our journey in identifying a sensible HCI model, let us trace back a bit the history of computer development. Computational technology has grown continuously in sophistication and complexity ever since the appearance of the first models of binary computers during the 1950 s. $^{2}$ Direct operation of giant electro-mechanical systems was succeeded by the invention of programs using symbolic coding, which subsequently gave way to the application of metaphoric couplings where text and graphics express computational commands to users. The changes taking place through different generations of computer design capture various dimensions of $\mathrm{HCI}^{3}$. More recent advances have aimed at making digital technology increasingly accessible to the public and thereby have significantly contributed to the popularity of all-in-one personal computing and the creation of a ubiquitous digitalized environment. Contributing to defining modern life, desktop computers, personal digital assistants (PDA), smart phones, ticket booths and central air conditioning systems are, by all means, like the air: everywhere and all around us. In spite of their actual mechanical complexity, user-"friendly" designs aim at erasing all operational complication. They seek to make it "effortless", like the inborn act of breathing, and to transform surreptitiously- our operation of them into an unconscious behavior.

Abstraction and interfacial coupling ${ }^{4}$ achieve simplification, which in turn contributes to user accessibility. Coupling is a way of establishing relations between functional entities, such that a chain of associations is formed linking otherwise disparate actions. The chain links body movement, mechanical design, electronic operation, symbolic manipulation and visual metaphors. The skill required by the user to fulfill computation is thereby diminished. Users can operate the system at skin level from the tip of the iceberg. The desktop model, which induces paralysis by restricting our physical body to one place -and seems to aim at some kind of physical absenting, suppression, vanishing, destruction-, conditions gestures and action to

2 Bruce Wands, "A Timeline of Digital Art and Technology", Art of the Digital Age, 210-211, Thames \& Hudson, New York, 2006.

3 Paul Dourish, "A History of Interaction.", In Where the Action is: The Foundations of Embodied Interaction, 1-11, The MIT Press, Cambridge, Massachusetts, London, England, 2001.

4 Dourish, "Foundations.", Where the Action is, 138-154. 
repetition ad absurdum, and with the internet has enabled us to connect to the outside world through couplings. This situation can potentially send the user into a secondorder world of representations and couplings, giving rise to the problem of virtual and disembodied cyberspace.

Often technology is a black box to users, who no longer understand the inner workings. These powerful black boxes have gradually become the backbone of convenient city life. They rapidly penetrate our being to reshape habits and semiotics. Meanwhile, we remain outside of them. It is not inherently wrong to apply simplified designs in certain practical contexts, but the inertia of operating at the surface as a rule discourages the moment-to-moment, situation-specific refinements of users and limits their creative performance potential. Consumerism further fuels the mindless drive towards technology. User-friendly products are designed for replacement and not repair. The sealed computation black boxes conceal conspiracies of designed and programmed obsolescence that fuel economic interests. Critics believe consumers are wickedly kept from this information to favor the corporations. However difficult it is to measure the current extent of such immoral activity, its role in depleting Earth's resources requires more attention. Taking preventive measures to discourage and penalize such wasteful behavior would be most fitting.

\section{Affordance and Affording Creativity}

Paul Dourish is a scholar of embodied interaction and ubiquitous computing. We turn our attention to his clarification of the term affordance. In addition, his adoption of Heidegger's phenomenological approach to meaning in everyday life can further illustrate the degree to which HCI design induces disembodiment, frustration, and alienation within real life settings.

According to Dourish, the psychologist J.J. Gibson defines affordance as a "property of an environment", , approached ecologically by a subject via visual perception. Subjects observe their environment and generate an understanding of the possible actions afforded by this environment in relation to their body. A jar in high position affords only some tall people to reach, the gap between the sofa and the floor affords only some small hands/ kids' hands to have the freedom of movement in that space, or the access to reach their lost toys there. Following Gibson's analysis, Donald Norman further explores this concept in this book The Design of Everyday Things (1988). Norman highlights the relation of form and function in the design of everyday objects and of human-computer interfaces. ${ }^{6}$ Affordance can be designed by thoughtful consideration and arrangement. Action and participation are partially determined by the potential embedded in an object by design. A cup handle affords an easy hand grasp. The shape and size of the handle is designed in proportion to the shape and size of the human hand. Therefore the shape of a hand affords the handle a range of possible shapes.

5 Dourish, "Being-in-the-World.", Where the Action is, 117.

6 Paul Dourish, "Being-in-the-World.", In Where the Action is, 118-119. 
I would soon argue here that instead of simply affording expected actions, a sensible HCI model must afford creativity and skill development. The notion of situated actions, expounded by British anthropologist Lucy Suchman, provides a firm axis from which to propound my argument. The framework emphasizes the importance of the specific normal context of situations. Computational designs are often built on the basis of the "antecedent conditions and the consequences of human actions" 7 . They work within a closed system of finite operational possibility, affording decision-making users a series of choices. By contrast, real life situations, under the continuous influence of complex social and environmental factors, involve a human communication and interaction impossible to pre-formulate. They are conversations that, to achieve an overall coherence of the person and the unit of computation require moment-to-moment adjustments and ongoing revision. Suchman's view is that sensible computational designs should serve as resources for situated actions without restricting their own local and circumstantial practical possibilities. At present, most computational units have preset limitations. It is important that users gain awareness of the limitations and find ways to compensate for them.

So what can users do after gaining this awareness of the computational limitation? Let us take a look at how it is exactly that people engage with their tools and computational devices through the lens of Heidegger's phenomenological concept of meanings in everyday life. Being-in-the-world (Dasein) is one of Heidegger's key concepts. We engage with the world by encountering meanings driven by practical affairs. The distinction between ready-to-hand (zuhanden) and present-at-hand (vorhanden) gives a more concrete description of the encounters. Dourish further applies Heidegger's conception literally to our use of tools, namely to computer interfaces. $^{8}$ A mouse works as an extension of its user's hand. Unreflective of the mouse's existence, the mouse is ready-to-hand to the user. Were the mouse to reach the edge of the table and the user to notice, the mouse would, if only fleetingly, appear to the user as present-at-hand. Dourish believes tools can function well only when they exist as ready-to-hand. ${ }^{9}$ This, I believe, is an oversimplified interpretation of the user/tool relation in the context of real situations. The relation is actually very unstable, and a shift between ready-to-hand and present-at-hand is continuously taking place. The user's world is highly complex. Often tools conceptually fuse, often they are conceptually severed, being in some way ready and present almost at once. More in tune with Suchman's notion of situated actions, we can investigate the way users engage with tools on a moment-to-moment basis, and leave aside the simplistic notion that tools become invisible when people are efficient.

The development and resultant ripeness of the technique with which a tool is used is dependent on repetition and refined through accumulated experience. The technique of writing with a pencil, for instance, is never ultimately stabilized and undergoes

\footnotetext{
7 Lucy Suchman, Human-Machine Reconfigurations: Plans and Situated Actions, 31,

Cambridge University Press, West Nyack, New York, USA, 2006.

8 Paul Dourish, "Being-in-the-World.", In Where the Action is, 106-110.

9 Ibid.
} 
ceaseless modification: there is improvement on the path to mastery, adjustment is a function of how frequently we write, different contexts demand different speeds, the surface of inscription plays a role, language has an influence over technique, recipient and destination impact effects, injury conditions.

In short, every encounter with a tool -itself a complex entity- involves a stabilizing and a destabilizing of skills, and every application of skill is influenced by a previous level of skill, by accumulated experience, and by the aim of the application. My experience of writing with a sharp pencil will influence the way I write with a blunt pencil. I may gradually apply less force on the pencil as it blunts to maintain an even line thickness. Moreover, the location of the writing in relation to our body changes throughout the writing action. In writing on a page from left to right and from top to bottom with a sharp pencil that blunts one stroke at a time, our technique is a function of our accumulating experience within a situation of absolute change that demands dynamic adjustment. Paradoxically, a static technique would only produce inconsistency. We destabilize the technique and reestablish it with subtle movements. An unrealistic linearity is implied by designs based on false notions of stability in a world of predictable imperatives. The strict model of solid design is bound to break by sheer pressure -for change is unrelenting.

The notion that a setting's affordance is not preset but changes over time as a function of experience (i.e. the user's encounters with objects within a context) is related to the aforementioned observation that using tools is a dynamic learning process requiring constant skill adjustment and development. A master ceaselessly returns to the novice stage. With an awareness of the nature and limitations of computation design, and through gradual acquisition of the skill of in situ embodiment, we prepare the ground for creative solutions to flourish. Prompted by Norman's idea of designing a cup handle's affordance, I hereby propose we endeavor consciously to afford this awareness of the nature and limitation of computation the power to afford us, artists and engineers the ability to design HCI platforms that afford creativity through the development of skills. The choices we make concerning technology and education are changing our future. Are we sufficiently aware that these factors interbreed and sensitive to the concomitant realities? Should we be content simply to transit mechanically from transient awareness to ready-to-hand invisibility?

\section{$4 \quad$ DIY and Studio Creativity}

Meanwhile, the practice of Do-It Yourself (DIY) and studio art can shed some light on how to incite the creativity of participants and how to promote innovative solutions and original interactions. The phrase "Do-It-Yourself", which already appears in a 1912 US advertisement, became common during the 50s. ${ }^{10}$ DIY referred at first to home improvement, decoration and maintenance work performed by householders

${ }^{10}$ Matt Watson and Elizabeth Shove, "Products, Competence and Meaning in the Practices of DIY”, Paper, European Sociological Association Torun 2005, Poland, 2005. 
who refrained from employing professionals. It has now been extended to other DIY activities like furniture production, clothes making and computer assembly. Matt Watson and Elizabeth Shove emphasize DIY's emergent character, and not budget concern, as a key motivation to people's involvement in production that can easily be out-sourced. ${ }^{11}$ In vein with Suchman's notion of situated action, Watson affirms that needs change in the context of local everyday practice, and therefore plans must be contingent and temporary.

He mentioned that in the process of completing a planned DIY project often reveals new needs, adjustment and jobs that needed to done before the planned tasks. The unpredictability of DIY practice further develops DIYers' competence and confidence, thus allows new possible DIY projects to evolve in the future. ${ }^{12}$ Enhanced by knowledge obtained from school, friends and family, and read about in DIY manuals and internet forums, such competence remains virtual until DIYers actively synthesize and harness their existing knowledge, experience and skills through practice and through engagement with tools, materials and the specific conditions of their DIY tasks.

"[DIY] is the work, of coordination of tools, materials, competence, confidence, body and the fabric of the home that places DIY at such a complex location in relation to the conventional boundaries of social scientific analysis, the boundaries between leisure and work, consumption and production, and ultimately between human and nonhuman." (Watson and Shove 2005)

Alongside this, the frugal DIY approach to technology in Cuba portrays another inspiring reality. Technological Disobedience ${ }^{13}$ is a term coined by Cuban Artist/Designer Ernesto Oroza in his study of the lifestyle of frugal innovation in Cuba in response to severe isolation and scarcity of resources since the $1960 \mathrm{~s},{ }^{14}$ when a vast number of American investors, professionals and technicians left Cuba. 'Disobedience' refers to a violation of a product's unity, a disregard for its aesthetic integrity, a lack of concern for safety and legal regulations and a willingness to take risks, and a breakthrough from the typical product-consumer model of other developed countries, overturning a closed system to break open and unleash unexpected unrealized solutions. Invention, reinvention, improvisation and repair are demonstrated by ordinary Cuban citizens, who display awesome skill in applying with novelty various materials and parts of complex machines. Their understanding of how things work coupled with an ability to extract an unlimited potential from limited resources is truly impressive. I was in Cuba for two weeks in 2008 and witnessed a makeshift fair with old amusement park rides in Pinar del Río. The machines looked exotic, most of them tattered and repaired, looking almost like oversized tin toys lit by

\footnotetext{
${ }^{11}$ Ibid.

12 Ibid.

13 "Ernesto Oroza, Technological-disobedience", Last modified January 28, 2014,

http: / /www. ernestooroza.com/category/technologicaldisobedience-project/

14 "Cuba's DIY Inventions from 30 years of Isolation", MotherboardTV, Last modified June 20, 2013, http: / /wn. com/exact/MotherboardTV
} 
tungsten light bulbs. Traces of repair were unabashedly exposed, a silver fork used to control a swinging ship, a few strong men using muscle power to start and to brake the ship, wires tied with knots from the rotational train to the central pole... All these surreal facts were fusing live with real Cuban music, and a cheerful and optimistic atmosphere ruled. [Fig.1] Like the artist that I am, I set out to capture my observations in video and began to design a way to display the video in a form that could evoke similar technological relations. I thought of constructing a six-channel video installation without the luxury of eight separate projectors. I appropriated several magnetic door stoppers to function as $360^{\circ}$ pivots and attached a tiny mirror to each one. [Fig.2] Each magnetic joint could be manipulated with precision to control the direction of reflection of the video projected onto its respective mirror, and simple hand adjustments could be made to adapt the installation to the height, width and depth of different rooms. It was first installed in a projection room close to my studio. I was aware of my limited budget and knew that fine video screens were beyond my grasp. While I puzzled over a solution, the A2 sketching papers on my studio desk caught my attention. The newspaper-like texture of the sketching papers matched surprisingly well my impression of Cuban style. For the presentation, I invited visitors to use these papers to capture the video projections reflected by the six tiny mirrors mounted on the magnetic pivots. The images had a sharp focus only if they were caught "in mid-air" by the papers, and looked blurred when they hit the walls. My guests walked around the room, viewing my video document of Cuban amusement machines as phantoms appearing on paper. [Fig.3] The work was named Warm Technology, to glorify a Cuban creativity that demonstrates a special reciprocal relationship between the people and their technological devices and system. Faced with an imperative for on-site adjustment, functional appropriations provide the needed flexibility and openness for a successful engagement with an otherwise deficient technology.

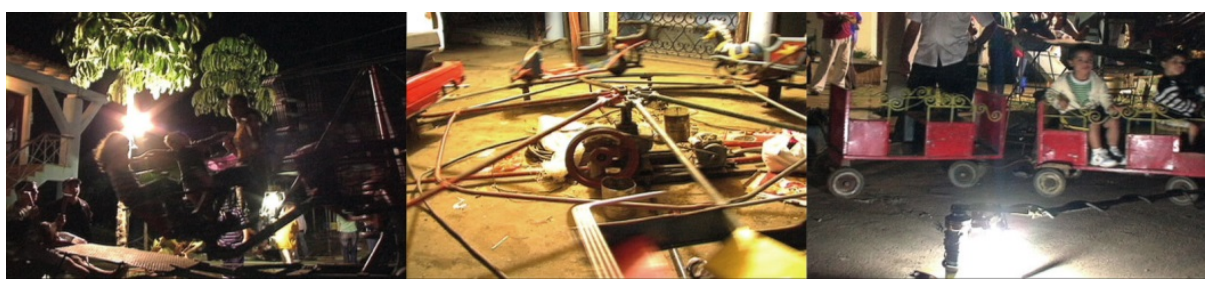

Fig. 1. Video Screenshots of Warm Technology, captured in Pinar del Río, Cuba, 2008

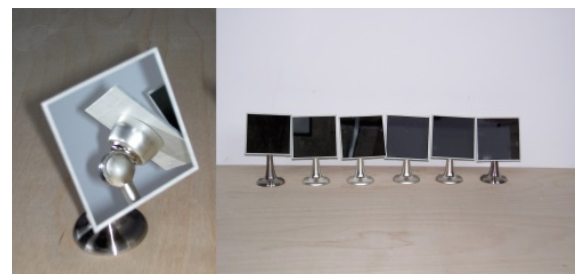

Fig. 2. Magnetic door stoppers with mirrors 


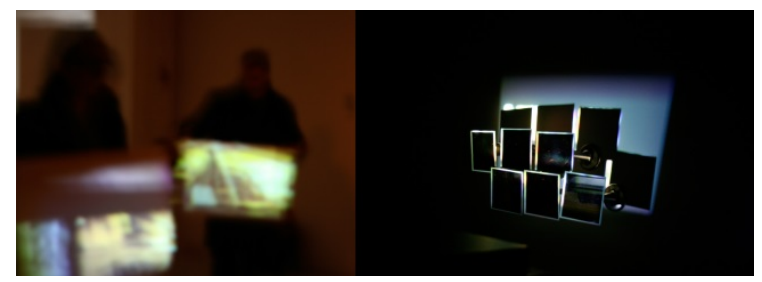

Fig. 3. Video Installation, Warm Technology

I have found the influence and merits of studio art practice central to the discussion of affordance of creativity to reflect a similar spirit. At the interface of meditative thinking and material engagement, of concept and bodily involvement, where stress is laid on the power of imagination and on promoting the development of new forms of expression, the exercise of problem finding and solving, of restricted and situational improvisation, finds a liberated space to manifest.

Reflecting in this light, I have set out in my own art practice as research vehicle to explore how computational interfaces and digital image displays afford creativity through a choice in setting. ${ }^{15}$ In several of my studio works I rethink and rework my own media. Aware of the idiosyncrasy of living in a computer age, and not wanting merely to display my seal with digital projectors on monitors, I built an image machine for visitors to actually enter and modulate, gaining thereby the peculiar ability to influence an iridescent image at hand on display. Named LSD (Liquid Soap Display) as a deviation from a sophisticated market product -the LCD monitor- it challenges the passive viewing practice pervading the industry of digital imagery by giving rise to an interactive dialogue between visitors and the image generated in situ in real time, made possible by the soap solution and the huge lens membrane generated. Moreover, I bring notice to the way viewers participate in the process of image perception at the physical, biological, and cognitive levels. In a different work called Wood Digit, I make a reference to early forms of the computer, like the Jacquard Loom, and to modern software packages so popular among new media artists. I designed a programming platform for generating sequences of patterns using thousands of interwoven nylon threads mounted on a wooden structure that allows control over the length of the threads, the programmed parameter of my artistic display. The weaving process was extremely tedious and technically challenging. I was constantly reminded of the gap between theory and practice, and found myself struggling between digital logic and physical properties. Problems arose at almost every step in the process to increase the load of an already labor-intensive project. It served as a complete studio training for me, in wood cutting, programmed laser cutting on plastic sheet, thread weaving, engineering, and mathematical calculation of programmed movement. Admittedly, I had to integrate most of the multi-disciplinary skills and knowledge I had learnt thus far. All these studio projects have allowed me and my visitors to think through technology. I strive in my work to afford creativity, in action and in thought. Furnishing a technology that affords creativity is a way of

15 “Zoie So- Art Laboratory”, Last modified in 2013, www . zoieart. com 
contributing to the design of humanity's humanity. The creative practice of DIY and studio art does more than merely provide a possible model for an HCI model that affords creativity. The enormous experience and acquired skills undertaken in both DIY and studio art practice equips a person with the competence and confidence needed to interact with computational technology in a way that furnishes creative solutions to unspecified local site-specific conditions.

\section{$5 \quad$ Modular Possibilities}

Preoccupied with openness and improvisation, Dourish urges designers to focus on providing means for exploiting appropriation and articulation of resources, that they may be incorporated into the practice specific to each situation, allowing users to reach and act upon the technology, and more importantly making possible the extraction, examination, manipulation and rearrangement of units. He asserts that coupling management and meaning construction should be relayed by designers to the users. Yet this kind of unmitigated transparency exposing users to a hard-core numerical programming language is impracticable and perhaps even impractical. ${ }^{16}$ The Cuban frugal approach, though fascinating, may not suit citizens of developed countries with sufficient resources and unwilling to risk safety and to challenge law. Dourish's alternative is to design a "macro" programming and thereby to increase the ability of users to define couplings and to participate in the design process. ${ }^{17}$ Along these lines, modular design provides flexibility between specificity and exchangeability. Acting upon electric sockets, which are a global variable, universal adaptors and transformers function as constants executing local and global coordination.

Modular Design is widely implemented in architecture and interior design, a common example being the mobile furniture units of office spaces. Workstations built from modules can respond to functional variations and can be both re-assembled and expanded upon to adapt to an ever-changing workforce. The units of modular design are not limited to a uniform shape. Bicycles and computers, for instance, take parts responding to functional variation and upgrading. Modular design commonly makes use of connectors with highly compatible standard links to mediate modules, a feature that makes recombination feasible, simple and economical. USB (universal serial bus) protocols, which allow interconnection of various computer and electronic devices, support both data and power transfer. The personal computer serves as a hub to link keyboard, mouse, external hard drive, printer, scanner, digital camera, bluetooth adapter, and can power or charge these devices simultaneously.

The model of modular design depicts an open system that in principle allows for unlimited incorporation of new modules, providing devices with the flexibility to adjust to situational demands. The USB device can double as a cooling fan, a hand

${ }^{16}$ Malcolm McCullough, "Technology: Situated Types", Digital Ground: Architecture, Pervasive Computing, and Environmental Knowing, 117-119, The MIT Press, Cambridge, Massachusetts, London, England, 2004.

${ }^{17}$ Ibid. 
warmer, an LED desk light, a keyboard mini dust-vacuum, a self-inflating pillow mounted on a laptop, all of it made possible by the open nature of the USB. This also contributes to reducing technological waste. Most current computational models follow the sealed blackbox design, purporting user-friendliness while perpetuating the wasteful practice of acquiring devices that cannot be repaired once damaged, or incur unreasonable repair costs, rendering useless a device with most of its parts intact. The absurd reality is that a new device is usually cheaper than repair of a broken one.

Concerned about the unnecessary waste generated in the smart phone market, a team of three members: Dave Hakkens, Gawin Dappe and Tomas Halberstad started a design group under the name of Phonebloks in 2013 that today boasts 979,260 supporters. ${ }^{18}$ The group is devoted to realizing a modular design for the smart phone, which they promote with the slogan "a phone worth keeping" 19 . Their modular design for smart phone has detachable blocks connected to a common base that holds everything together. Modular blocks are self-contained, and each works as a separate Wi-Fi, Bluetooth, battery, operation speed, data storage, antenna or audio unit. Users can customize, upgrade and repair each phone block independently. Ideally, with different companies contributing to the development of these functional blocks, users could enjoy great liberty in choosing and composing blocks, and could go as far as to design their own. Technological functions are broken down into units and can be recognized and studied separately, allowing users themselves to determine the coupling of visual metaphors and the assignment of semantic values, as the device's mode of operation is itself revealed through operation. This kind of open modular system serves genuinely as a root for creative potential and provides ample resources for high exchangeability in multiple and varied cases.

\section{Conclusion}

The metaphor put forth by American scholar Malcolm McCullough further enriches our musings over designs of computer interaction: Classical musical instruments facilitate personal growth and increase creativity through skill practice, and this creativity flourishes when bodily engagement is tightly channeled through the physicality and nature of the instruments. ${ }^{20}$ The experience is a tangible one of sense making. Musicians are encouraged to mediate with and to understand their instruments, and not to look at them merely as responsive devices, as means to solving problems promptly or performing a specific task.

Our ever-changing world demands embodied responses to various moment-tomoment conditions that require a semiotic understanding. Computer design is to consider local and global compatibility and the adjustments specific to their respective nature. The flexibility and openness of models such as modular design afford customization, sensitive appropriation and improvisation. In DIY and studio art practice artists generate the know-how needed to accomplish tasks, as they engender

\footnotetext{
18 "Phonebloks", Accessed February 10, 2014, https : / / phonebloks.com/en

${ }^{19}$ Ibid.

${ }^{20}$ McCullough, “Technology: Embedded Gear”, Digital Ground, 85.
} 
awareness of materiality through first-hand involvement and deep reflection upon the relation of consumer and product.

A sensible HCI model would afford users the power to engage with computers in a flow of creativity that exploits experience and acquired skills. In furthering competence and confidence through active engagement with computational devices and the environment, creative solutions and original situations emerge in the process. Sensible HCI designs require a degree of understanding that discourages oversimplification and ultimately resists the inertia of ignorance. Human interactions with computers are to advance a platform wherefrom to generate sense and meaning. Through embodiment, skill development and reflection on the nature of the relation, this platform is to be a stepping stone for human creativity. To afford creativity is not to enforce patterns. Rather, it is a freedom-favoring way to design how we want to be, for ourselves and the generations to come: open.

\section{References}

1. Wands, B.: A Timeline of Digital Art and Technology. Art of the Digital Age, pp. 210-211. Thames \& Hudson, New York (2006)

2. Dourish, P.: Where the Action is: The Foundations of Embodied Interaction. The MIT Press, Cambridge (2001)

3. Suchman, L.A.: Human-Machine Reconfigurations: Plans and Situated Actions. Cambridge University Press, West Nyack (2006)

4. Watson, M., Elizabeth, S.: Products, Competence and Meaning in the Practices of DIY, Paper, European Sociological Association Torun 2005, Poland (2005)

5. Ernesto Oroza-Technological Disobedience, http: / /www. ernestooroza.com/category/ technological-disobedience-project/

6. Cuba's DIY Inventions from 30 years of Isolation, http: / /wn.com/exact/MotherboardTV

7. Zoie So- Art Laboratory, http: / / www . zoieart. com

8. McCullough, M.: Digital Ground: Architecture, Pervasive Computing, and Environmental Knowing. The MIT Press, Cambridge (2004)

9. Phonebloks, https://phonebloks.com/en 